\title{
Potentiality of secondary ion mass spectrometry for chemical, micron-size imaging of multiphase polymer materials
}

\author{
J. Marien ${ }^{1, \star}$, G. Ghitti ${ }^{2}$, R. Jérôme ${ }^{2}$, and Ph. Teyssié ${ }^{2}$ \\ 'Laboratory of Physico-Chemistry of Surfaces, Department of General Chemistry, and ${ }^{2}$ Center \\ for Education and Research on Macromolecules, (C.E.R.M.), University of Liège, Sart-Tilman, \\ B-4000, Liège, Belgium
}

\section{Summary}

Thin deposited films of the diblock copolymer poly\{methylmethacrylate-b(2,perfluorohexyl-ethyl)acrylate blended into a poly (methylmethacrylate) matrix were studied by Secondary Ion Mass Spectrometry. The molecular information contained in the negative spectrum and peaks ratio measurement identify the top surface as being saturated with fluorinated chains. A multiphase morphology was also revealed by ion microscopy. The potentiality of Secondary Ion Mass Spectrometry to provide chemical images of micron-sized phases in polymer materials is nicely demonstrated.

\section{Introduction}

Blending into a homopolymer a selected block copolymer of which one block is expected to surface segregate and the other one to interact with the matrix is an interesting way to tailor new materials. The development of that aspect of macromolecular engineering relies upon the synthesis, the incorporation and the ultimate segregation of adequately tailored copolymers but also on the availability of penetrating techniques to analyse polymer surfaces and interfaces. A full qualitative description of the surface of such multicomponents systems requires at least two major steps. First, the chemical species present on the surface must be identified. Therefore, surface techniques capable of molecular information are needed. In the past, X-Ray photoelectron spectroscopy (X.P.S.) was the conventional technique (1). Secondary Ion Mass Spectrometry (S.I.M.S.) appears now to be a powerful, complementary technique with some unique potentialities. Static S.I.M.S. (S.S.I.M.S.) (2) introduced by A. Benninghoven for the study of inorganic (3) and organic (4-5) surfaces delivers a direct and detailed molecular information of the outermost surface $(10 \AA)$ of polymers (6-7). The second step consists in revealing the possible "superficial" multiphases. Indeed, polymer alloys and blends are most often multiphase materials (8-9). The conventional techniques of electron microscopy only provide physical images and there is an imperious need to find techniques capable of sub-micron chemical imaging. S.I.M.S. images of polymer microphases are very scarce (10-11).

The technique nevertheless has that potentiality. Several requirements must be fulfilled to image polymer microphases. Besides finding a system with favourable surface thermodynamics, microprobes or ultimate resolution (0.35 micron) (12-13) ion microscopes have to be used because the phases are most often submicron (8) sized. Due to that small size of the probe, a sensitivity problem (14) is faced so that only the highest ion yield species are useful for imaging.

Here, we report preliminary S.I.M.S. results about the surface chemistry of thin films made of a fluorinated copolymer blended into a polymethylmethacrylate (PMMA) matrix. Besides the molecular characterization of the top layers, we have succeeded in recording chemical images of micron-sized polymer phases. 


\section{Experimental}

Thin films of the diblock poly \{methylmethacrylate-b- (2,perfluorohexylethyl)acrylate\} copolymer blended within a PMMA matrix were prepared by evaporation of tetrahydrofuran solutions on a tungsten substrate. Details about the copolymer's synthesis can be found elsewhere (15). Blends in which the overall weight concentration in copolymer ranges from 0.04 to $25 \%$ were studied by S.I.M.S.. Two instruments were used : Riber (Q156) quadrupole previously described (16) and I.M.S.4F (Cameca) used in the ion microscope mode (12). Positive S.S.I.M.S. specta and ratios of negative atomic ions were measured with the quadrupole instrument equipped with a primary argon beam $\left(4.5 \mathrm{KeV}, 5 \cdot 10^{-9} \mathrm{~A} \cdot \mathrm{Cm}^{-2}\right)$ and $2 \mathrm{KeV}$ electron flooding. Molecular negative secondary ions recording and high resolution imaging were performed with the magnetic sector using a primary cesium source $(14.5 \mathrm{KeV})$ and automatic charge compensation by a coaxial electron gun (17).

\section{Results and discussion}

As shown in Fig. 1, the negative S.S.I.M.S. spectrum is characteristic of a highly fluorinated polymer surface. The $\mathrm{F}^{-}\left(2.410^{5} \mathrm{c.s}-1\right)$ peak and numerous fluorinated ion fragments whose structure is depicted in Table 1 dominate the fingerprint.

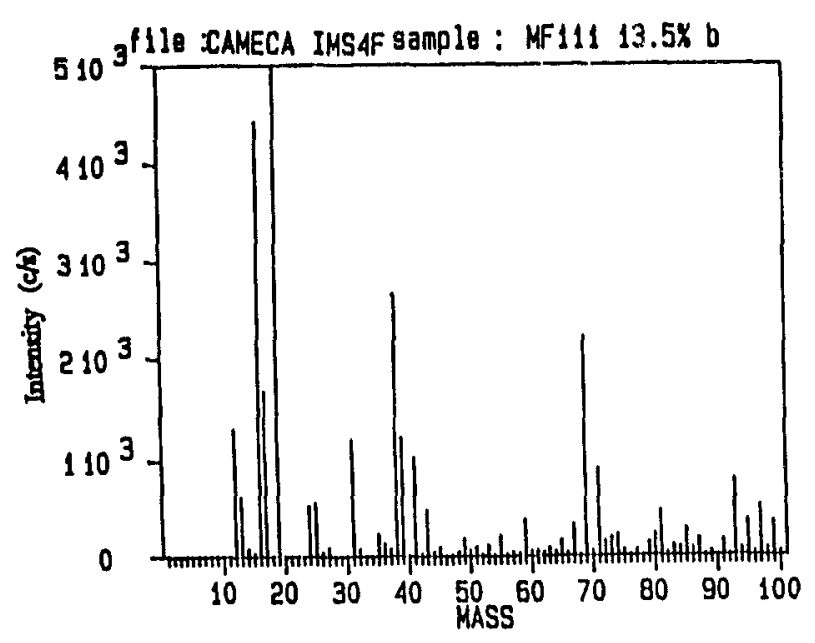

Fig. 1. First 100 a.m.u., negative S.S.I.M.S. spectrum of an evaporated thin film of copolymer (13.5 w \%)/ P.M.M.A. blend. $\left(\mathrm{Cs}^{+}, 14.5 \mathrm{keV}^{-} 70^{-12} \mathrm{~A}\right.$, $210^{12}$ ions.cm- ${ }^{2}$ ) 
Table 1. Structures of the main negative ions present in the spectrum shown fig. 1

\begin{tabular}{|c|c|c|c|}
\hline a.m.u. & ion structure & a.m.u. & ion structure. \\
\hline 12 & $\mathrm{C}^{\circ}$ & 39 & $\mathrm{HF}_{2}{ }^{-}$ \\
\hline 13 & $\mathrm{CH}^{-}$ & 41 & $\mathrm{HC} \equiv \mathrm{C}-\mathrm{O}^{\circ}$ \\
\hline 16 & $0^{-}$ & 43 & $\mathrm{C}_{2} \mathrm{~F}^{-}$ \\
\hline 17 & $\mathrm{OH}^{\circ}$ & 69 & $\mathrm{CF}_{3}^{-}$ \\
\hline 19 & $F^{*}$ & 71 & $\mathrm{CH}_{2}=\mathrm{CH}-\mathrm{CO}_{2}^{-}$ \\
\hline 24 & $\mathrm{C}_{2}^{-}$ & 81 & $\mathrm{C}_{2} \mathrm{~F}_{3} \cdot$ \\
\hline 25 & $\mathrm{C}_{2} \mathrm{H}^{-}$ & 93 & $\mathrm{C}_{3} \mathrm{~F}_{3}$. \\
\hline 31 & $\mathrm{CF}^{-}$ & 105 & $\mathrm{C}_{4} F_{3}^{-}$ \\
\hline 38 & $\mathrm{~F}_{2}-$ & $\begin{array}{l}171 \\
171\end{array}$ & $\begin{array}{c}\mathrm{CsF}_{2}^{-} \\
\mathrm{CH}_{3} \\
\mathrm{CH}_{3}-\mathrm{C}-\mathrm{CH}=\mathrm{CH}-\mathrm{CO}_{2}^{-} \\
\mathrm{CO}_{2}^{-} \mathrm{CH}_{3}\end{array}$ \\
\hline
\end{tabular}

A detailed examination however reveals the neighbourhood of some $\mathrm{CF}_{2}$ and $\mathrm{CH}_{2}$ groups (presence of $\mathrm{HF}_{2}^{-}$besides $\mathrm{F}_{2}^{-}$). The pattern, close to teflon but with some poly(vinylidenedifluoride) features identifies undoubtedly the surface acrylate ester chains. Positive S.I.M.S., not shown here, corroborates that result. Nevertheless, the negative spectrum is still more instructive because it shows that acrylate blocks are close to the top surface. Indeed, the intense anion at 71 a.m.u. mainly points out the acrylate whereas the weak methacrylate anion ( 85 a.m.u.) suggests a lower surface amount in PMMA block or matrix. That conclusion is plausible as the fingerprints comparison between PMMA and poly(ethylacrylate) shows a higher ion yield for the 85peak. In the case of the copolymer-matrix blend, a signal appears at 171 a.m.u. which is much less intense for the pure copolymer. That ion adduct (see Table 1) probably results from interactions betwween acrylate chains and PMMA matrix. This however has to be confirmed by further experiments since there is a possible interference with $\mathrm{CsF}_{2}{ }^{-}$due to the primary beam. In order to estimate the relative surface concentration in fluorinated copolymer, we measured the ratio between $\mathrm{F}^{-}$and $\left(\mathrm{C}^{-}+\mathrm{CH}^{-}\right)$.

As demonstrated elsewhere (15), a linear relationship exists between that ratio and the fluorine coverage. Fig. 2 shows a constant $\mathrm{F}^{-} /\left(\mathrm{C}^{-}+\mathrm{CH}^{-}\right)$value whatever the initial copolymer bulk concentration in the blend.

It means that the >thin film's surface is saturated with fluorinated acrylate chains even for a copolymer concentration as low as 0.5 weight \%. During solvent evaporation, surface segregation of the copolymer macromolecules likely occurs owing to the low surface energy of the fluorinated chains. This also agrees with preliminary X.P.S, contact angle and Ion Scattering Spectrometry results (15); the only slight difference being due to the depth of information characteristic of each technique.

Besides, the surface layers of the copolymer (13.5 w \%)/PMMA blend have been imaged at high resolution $(5000 \AA)$ with the ion microscope. The $\mathrm{F}^{-}$image shows that fluorine is not homogeneously distributed i.e. phase separation occurs. This can be seen in Fig. 3 where bright regions, about 15 microns in size, refer to fluorine rich phases. One also notices that the $\mathrm{F}^{-}$globules cover the surface almost completely. The $\mathrm{C}^{-}$ image, not shown here, is just the reverse : to bright $\mathrm{F}^{-}$spots correspond dark $\mathrm{C}^{-}$ regions. 

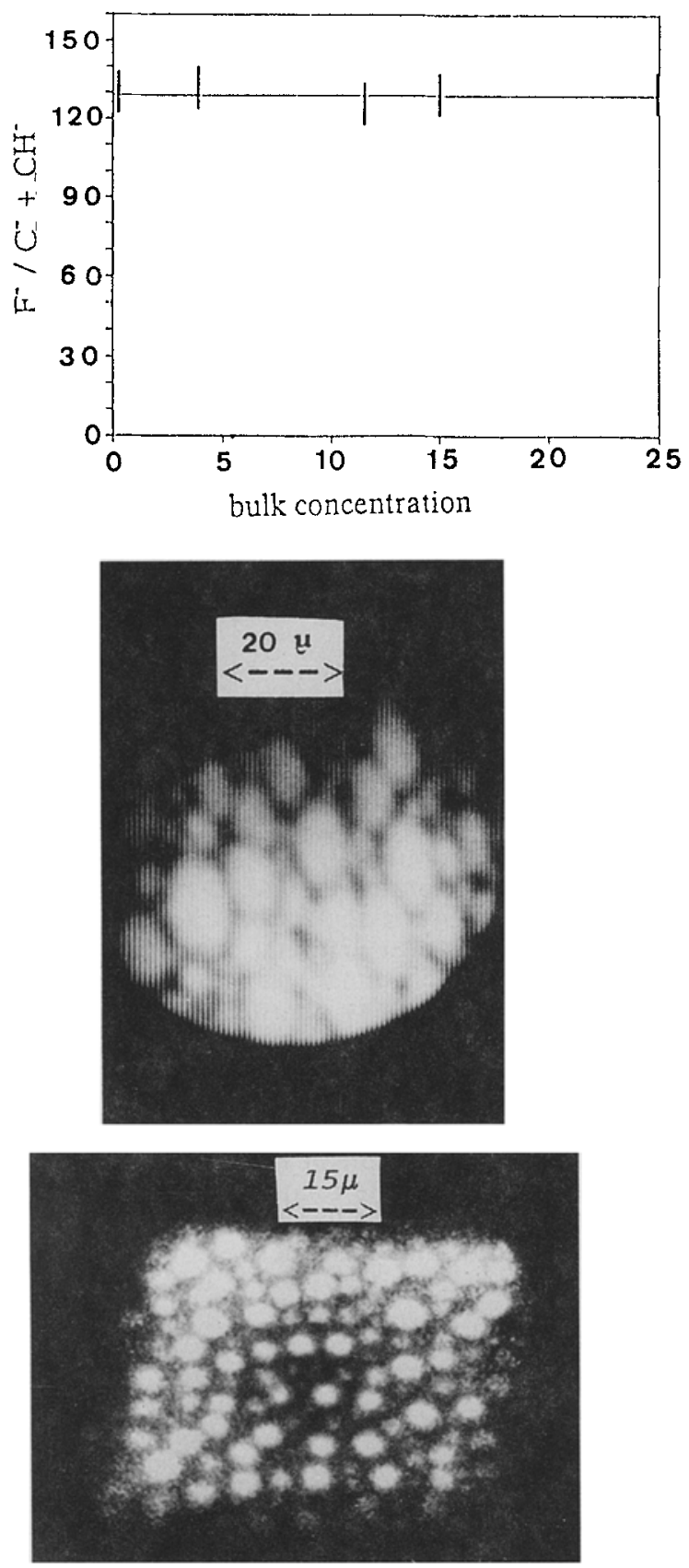

Fig. 2. Peak heights ratio $\left(\mathrm{F} / \mathrm{C}^{-}+\mathrm{CH}^{-}\right)$versus the overall bulk concentration (w \%) of copolymer in a series of blends.
Fig. 3.

Ion microscopy of the top layers of a blend containing $11 \mathrm{w} \%$ in copolymer. $\left(\mathrm{Cs}^{+}, 14.5 \mathrm{keV}, 41^{-9}\right.$ ampere $10^{-5}$ ampere.cm-2 less than 10 seconds of erosion).

$F^{-}$image showing on set of phase separation.
Fig. 4.

$\mathrm{F}$ image of a blend containing $13.5 \mathrm{w} \%$ in copolymer after 2 minutes of bombardment. The bright spots correspond to a few microns fluorinated phases. 
This rules out that a topographical effect is observed. Nevertheless, it must be taken into account that the imaging conditions are relevant to dynamic S.I.M.S. and not S.S.I.M.S. Although we do not know the sputtering rate, it is likely that a few "monolayers" are eroded during the time needed to take a Polaroid photograph. While bombardment is going on, one observes a rather fast evolution in the F-image; the size of the fluorinated phases decreases while the picture gets sharper and more contrasted. This is illustrated in Fig. 4 which exhibits 5 microns $F^{\circ}$ bright spots after two minutes of sputtering. Finally, after about six minutes of erosion, the fluorine image becomes rather uniform without any large bright spot visible.

A tentative explanation of the above results is that the top layers consist almost exclusively in the fluorinated chains. Just below, in the still copolymer enriched layers, micron sized separated phases are imaged while, deeper in the film, micelles predominate. The latter, likely smaller than $1000 \AA$, cannot however be resolved. For some copolymer-homopolymer blends, surface segregation of micelles (18) has been indeed demonstrated by electron microscopy. Here, the strong surface segregation of several micelles layers perhaps enables the development of a bulk, three-dimensional microdomain morphology in the selvedge. An attractive interaction between micelles could be accompanied by the onset of macrophase separation of micelles/homopolymer mixture (18).

\section{Conclusions}

The results reported here are preliminary, especially with regard to imaging, but nevertheless attractive. They, not only, confirm the usefulness of S.S.I.M.S. for molecular characterization of the top surface but they also demonstrate that S.I.M.S. can be a technique for chemical sub-micron size imaging of multiphasses polymers. Owing to the measured $F^{-i n t e n s i t y, ~ i t ~ s e e m s ~ r e a l i s t i c ~ t o ~ i m a g e ~} 1000 \AA$ size phases. Besides, not only surface but also bulk microphases could be imaged providing a reliable cross section of the solid is feasible.

Although a tentative explanation has been suggested, a definitive model of the morphological structure of the superficial layers and a complete understanding of the imaging results are still lacking.

In a further work, it would be worth to image with a less energetic probe in more static conditions. Time of flight S.I.M.S. (T.O.F.) would be a valuable tool to acquire simultaneously images and spectra with minimum consumption of matter. In particular, it is necessary to check if the energetic primary beam takes some part in the formation, evolution of the imaged structures. T.O.F. should minimize the deposited energy and the subsequent induced radiation damages. Besides, any possible local rise in temperature could be avoided. Working at low temperature, might be a helpful condition when imaging polymer materials.

Nevertheless, working with the magnetic sector ion microprobe is very convenient when not only the extreme surface but also the underneath layers have to be imaged.

\section{Acknowledgements}

One of the authors (J.M.) thanks the National Fund For Scientific Research (Belgium) for the financial support of that study. Besides, we are greatly indebted to S.A. Cameca which allowed us to perform most of the work in its Applications Laboratory at Courbevoie (France). 


\section{References}

1. Briggs D. Practical Surface Analysis . Edited by D. Briggs and M.P. Seah, vol.1., $2^{\text {nd }}$ edition, John Wiley, 1990

2. Vickerman J.C. Methods of surface analysis. Edited by J.M. Walls . Cambridge Univ. Press, 1989

3. Benninghoven A. Surf. Sci. 1971, 28, 541

4. Marien J., Analysis, 1986, 14, 317

5. Benninghoven A., Sichtermann W. Anal. Chem .1978, 50, 1180

6. Briggs D., British Polymer Journal, 1989, 21, 3

7. Hearn M.J., Briggs D., Ratner B., Yoon S.C., Surf. Interface Anal. 1987, 10, 384

8. Jérôme R., Fayt R., Teyssié Ph., Chimie Nouvelle, 1990, 853

9. Coulon G., Russel T.P., Deline V.R., Green P.F. Macromolecules, 1989, 22, 2581

10. Marien J. Luxembourg SIMS Symposium, 29 juin 1992

11. Jackson S.T., Short R.D., J.Mater.Chem. 1992, 2, 259

12. Slodzian G., Ann. Phys. 1964, 9, 591

13. Migeon H.N., Schuhmacher M., Le Goux J.J., Rasser.B., Fresenius Z., Anal.Chem. 1989, 333, 333

14. Briggs D., Hearn M.J., Surf.Interface Anal. 1988, 13, 181

15. Ghitti G., Jérôme R., Teyssié Ph., Marien J., submitted for publication

16. Marien J., De Pauw E., Bull.Soc.Chim.Belg. 1979, 88, 115

17. Slodzian G., Cameca News, May 1987, 1

18. Shull K.R., Winey K.I., Thomas E.L., Kramer E.J. Macromolecules 1991, 24,2748

Accepted January 18, 1993 C 